\title{
Téoros
}

Revue de recherche en tourisme

\section{Les aménagements touristiques}

Phénomènes de génération spontanée ou produits de concertation

\section{Yves Archambault}

Volume 2, numéro 3, octobre 1983

Les multiples facettes de l'aménagement touristique

URI : https://id.erudit.org/iderudit/1080821ar

DOI : https://doi.org/10.7202/1080821ar

Aller au sommaire du numéro

Éditeur(s)

Université du Québec à Montréal

ISSN

0712-8657 (imprimé)

1923-2705 (numérique)

Découvrir la revue

Citer ce document

Archambault, Y. (1983). Les aménagements touristiques : phénomènes de génération spontanée ou produits de concertation. Téoros, 2(3), 1-1.

https://doi.org/10.7202/1080821ar d'utilisation que vous pouvez consulter en ligne.

https://apropos.erudit.org/fr/usagers/politique-dutilisation/ 


\section{Présentation}

\section{Les aménagements touristiques}

\section{Phénomènes de génération spontanée ou produits de concertation}

Sile dernier numéro de Téoros a mis en /umière les attractions touristisques du Québec, sil'on a tenté de faire la part des choses entre attractions et attraits ("), si enfin /'on accepte que les touristes, ces nomades imprévisibles, se laissent tenter par ou se lassent des mêmes attraits ou attractions, il ne faut pas pour autant conclure qu'en matière d'aménagements touristiques, tout est mode, hasard ou ressource naturelle. Du moins, c'est ce que les planificateurs, ces recréateurs de l'environnement, veulent bien essayer de démontrer, eux qui parfois échafaudent des projets grandioses sur de maigres points d'appui nature/s.

"Si la montagne ne vient pas vers toi, va vers la montagne!" Ces mots du prophète ont bien sür guidé plus d'un qui ont misé sur des valeurs sûres pour attirer des touristes avides d'assouvir leur curiosité, qui pour des phénomenes naturels, qui pour des lieux historiques, qui pour des modes de vie différents, qui encore pour des activités programmées, dirigées, digérées. A l'inverse, l'on ne compte plus les téméraires qui ont choisi le chemin combien plus hasardeux de la création, voire du déplacement des attractions. Sila tour Eiffel pointe toujours dans le ciel de Paris, ce n'est pas faute d'acheteurs pour la déplacer. Et pour une tour en place, combien de ponts de Londres, de cháteaux en Espagne ou, plus modestement, de cabanes de rondins n'a-t-on pas déplacés pour faire jailir la source miraculeuse qui fera retentir le bip bip de la caisse enregistreuse électronique?

En matière d'aménagements touristiques, il n'y a bien sûr pas de recette magique. La soupe aux gourganes attire-telle plus, moins ou autant de touristes que le dernier né des gorilles du zoo de Saint-Félicien? Bien malin qui pourrait $y$ répondre, et ce ne sont certainement pas les futurologues qui pourraient y voir clair dans leur boule de crystal. Ce qu'ils y trouvent dans cette boule, cependant, aidés en celà de tous les éminents spécialistes, urbanistes, économistes ou autres, c'est que, s'il suffit d'ouvrir le robinet pour remplir la baignoire, il ne faut pas oublier d'en fermer le bouchon d'évacuation. Ainsila plus belle pente de ski ou la plus belle plage ne seront jamais autre chose qu'une montagne parmi tant d'autres ou des milliards de grains de sable, tant que Ion n'en aura pas assuré l'acces et l'exploitation.
Brefl après ce long préambule, est-ïl encore nécessaire de préciser que le présent numéro de Téoros est consacré a l'aménagement touristique plutôt qu'aux aménagements touristiques? Les collaborateurs de ce numéro se sont donnés pour mission d'élargir le débat de l'aménagement en le faisant porter spécifiquement sur le tourisme. La relation Tourisme-Aménagement se situe a plusieurs niveaux. On connait l'importance du tourisme comme moteur économique de certaines régions. On a davantage sous-estimé /im. portance du tourisme comme outil de développement des autres secteurs. Bien souvent, des régions se sont vues dotées d'infrastructures nécessaires a la desserte de leurs potentiels touristiques, lesquelles infrastructures ont par la suite donné naissance à d'autres types d'investissements. L'inverse est d'ailleurs également vrai. Quoi qu'il en soit, l'importance du tourisme sur l'aménagement ne fait aucun doute, et surtout dans le contexte d'une nouvelle orienta. tion qualifiée de tourisme social ou encore de linterpénétration entre villegiature et tourisme.

L'aménagement des aménagements se pose d'autant plus comme priorité que lon est à mettre en place au Québec des superstructures d'aménagement de tous acabits au niveau des municipalités régionales de comté. Avec tous ces planificateurs en place, la nature n'a qu'à bien se tenir! D'icipeu, cependant, les plans devront faire place aux nou. velles réalisations. I/ est à espérer que les plans seront réalistes et réalisables!

Yves Archambault
11) Voir le texte de Marc Laplante dans le precédent numero de Ttoros, vol. 2, no 2. p. 14 